\title{
Pre-harvest fruit bagging influences fruit color and quality of apple cv. Delicious
}

\author{
Ram Roshan Sharma ${ }^{{ }^{*}}$, Ram Krishna Pal ${ }^{2}$, Ram Asrey$^{1}$, Vidya Ram Sagar ${ }^{1}$, \\ Mast Ram Dhiman ${ }^{3}$, Mani Ram Rana ${ }^{4}$ \\ ${ }^{1}$ Division of Post Harvest Technology, Indian Agricultural Research Institute, New Delhi, India; \\ *Corresponding Author: rrs fht@,rediffmail.com \\ ${ }^{2}$ National Research Centre for Pomegranate, Solapur, India \\ ${ }^{3}$ IARI Regional Research Station, Katrain, India \\ ${ }^{4}$ Pomologist and Fruit Grower, Baragaon, Kullu, India
}

Received 9 May 2013; revised 10 June 2013; accepted 15 July 2013

Copyright (C) 2013 Ram Roshan Sharma et al. This is an open access article distributed under the Creative Commons Attribution License, which permits unrestricted use, distribution, and reproduction in any medium, provided the original work is properly cited.

\section{ABSTRACT}

An attempt was made to observe the effect of pre-harvest bagging with spun-bound fabric bags on color and quality of Delicious apple. Bagging was done about a month before harvesting and removed 3-day before harvesting. Bagged and non-bagged fruits were stored at $2^{\circ} \mathrm{C} \pm 1^{\circ} \mathrm{C}$ and $90 \%-95 \% \mathrm{RH}$. Observations were recorded on color and fruit quality attributes such as total phenolics, AOX activity, fruit $\mathrm{Ca}$ contents, LOX activity, SSC and ascorbic acid contents at harvest and during storage. Our studies have revealed that bagged fruits have better color development (Hunter "a" = 52) than non-bagged fruits at harvest (Hunter "a" $=38$ ), which declined slightly during storage. Similarly, at harvest, bagged fruits contained high amounts of Ca $(5.38 \mathrm{mg} / 100 \mathrm{~g})$ and total phenolics $(9.3 \mathrm{mg}$ GAE/100g pulp) exhibited higher AOX activity $\left(12.6 \mu\right.$ moles Trolox $\left.~^{-1}\right)$, and had better SSC and ascorbic acid contents than non-bagged fruits, and there was a decline in all recorded parameters during storage. Bagged fruits exhibited lower LOX activity (1.38 $\mu$ moles $\left.\min ^{-1} \mathrm{~g}^{-1} \mathrm{FW}\right)$ at harvest than non-bagged fruits $(2.14 \mu$ moles $\min ^{-1} \mathrm{~g}^{-1} \mathrm{FW}$ ), indicating that non-bagged fruits were more senescent than bagged fruits. Further, LOX activity increased during storage both in bagged and non-bagged apples but increase in LOX activity was slower in bagged apples than in non-bagged apples.

Keywords: Apple; Fruit Bagging; Color; Firmness; LOX Activity; AOX Activity; Fruit Quality

\section{INTRODUCTION}

Apple is considered as one of the most important fruit crops of the world. In India, it is the $5^{\text {th }}$ most important fruit crop, which is grown primarily in hilly states like Himachal Pradesh, Jammu and Kashmir, Uttrakhand, northern-eastern states and to some extent in hilly regions of south India. From hills, the fruits are transported to plains for storage or marketing [1]. Red colored apples are preferred in the market as these attract the consumers. However, at lower elevations, color development is not adequate, and hence, majority of the farmers use ethrel (2-Chloroethyl Phosphonic Acid) as the pre-harvest foliar spray for color enhancement of the fruits. Ethrel helps in the development of attractive red color in apple fruits but it causes several adverse effects. For example, it enhances fruit drop, pre-mature leaf-fall, besides, the harvested fruits are of poor keeping-quality, and such apples need to be harvested at a stretch to get desirable price in the market [1]. Further, apples suffer badly from several post harvest diseases and disorders during storage and transportation, for which several chemicals and fungicides are used. These chemicals and fungicides may cause severe health problems to consumers. Hence, efforts worldwide have been started to find out some non-chemical approaches to reduce the incidence of diseases and disorders in fruits including apple [2].

Of several such alternatives, pre-harvest fruit bagging has emerged as one of the best approaches in different parts of the world. In this technique, individual fruit or fruit bunch is bagged on the tree for a specific period to get desired results. It is a physical protection technique commonly applied to many fruits, which not only improves fruit visual quality by promoting fruit coloration but also enhances internal fruit quality [3-8]. Pre-harvest bagging of fruits has been conventionally practiced for 
fruit growing in Japan, Australia and China as well as in peach, apple, pear, grape and loquat cultivation in order to optimize fruit quality through reduced physiological and pathological disorders and for improving fruit coloration to increase their market value [5] leading to improved appearance [7]. Several authors have reported contradictory results for the effects of pre-harvest bagging on fruit size, maturity, peel color, flesh mineral content and fruit quality, which may be due to differences in the type of bag used, the stage of fruit development when it was bagged, duration of fruit exposure to natural light after bag removal (before harvesting), and/ or fruit- and cultivar-specific responses $[4,9,10]$. Hence, attempts have been made to observe the effects of colored spun-bounded fabric bags on color and quality of Delicious apple, which is most abundantly grown in India.

\section{MATERIALS AND METHODS}

\subsection{Experimental Site and Fruit Material}

This study was conducted in the Division of Post Harvest Technology, Indian Agricultural; Research Institute, New Delhi-110 012, India during 2010-2012. In both the years, "Delicious" apples were bagged on-thetree with spun-bounded light-yellow colored fabric bags, 30 days before the expected date of harvesting ( $15^{\text {th }}$ July) every year in a private orchard at Kullu, Himachal Pradesh (India). Such bags have performed well in terms of retention of color and other quality attributes in our preliminary studies. The bags were removed 3 days before the expected date of harvesting. 50 percent fruit on individual tree were bagged and rests were not bagged. Each bag treatment was given to 5 trees with three replications. Every possibility was ensured for uniform distribution of bags in the tree-directions and canopy heights. During the period of bagging, trees were subjected to routine cultural practices.

\subsection{Observations Recorded and Methodology}

The observations on fruit color, firmness, Calcium (Ca) content, lipoxygenase (LOX) activity, and fruit quality attributes such as soluble solid content (SSC), total phenolics, antioxidant (AOX) activity, ascorbic acid (AA) contents were recorded in bagged and non-bagged apples at harvest. Then, apples were stored in cold storage $\left(2^{\circ} \mathrm{C}\right.$ and $90 \% \pm 5 \%$ relative humidity) for six months. At the end of $6^{\text {th }}$ month of storage, apples were removed from cold store and observations were recorded on abovementioned parameters.

\subsubsection{Determination of Fruit Color}

Fruit color in apple peel was measured from 20 ran- domly selected apples. The parameters CIELab: L $^{*}, \mathrm{a}^{*}$ and $\mathrm{b}^{*}$, were measured with a CR-200b tristimulus reflectance colorimeter (Minolta, Osaka, Japan). The parameter $\mathrm{L}^{*}$ indicates brightness or lightness $(0=$ black, $100=$ white), $\mathrm{a}^{*}$ indicates chromaticity on a green (-) to red $(+)$ axis, and $b^{*}$ indicates chromaticity on a blue $(-)$ to yellow axis $(+)$.

\subsubsection{Determination of Fruit Firmness}

Fruit firmness was determined in 20 randomly selected fruits with peel on both cheeks, using a texture analyzer (model: TA + Di, Stable micro systems, UK) using compression test and represented as $\mathrm{N}$ (Newton) (Sharma et al., 2012). Each run was a replicate of 3 samples.

\subsubsection{Determination of Total Phenolic Content, and AOX Activity}

Total phenolics of the fruit extracts were determined by the Singleton and Rossi method [11] with some modifications, and expressed in $\mathrm{mg}$ of gallic acid equivalents (GAE)/100g of extract. Antioxidant capacity was determined by following CUPRAC method [12], and expressed as $\mu$ mol Trolox $\mathrm{g}^{-1}$.

\subsubsection{Estimation of $\mathrm{Ca}$ Concentration in Fruit}

Fruit $\mathrm{Ca}$ content in bagged and non-bagged fruits were determined as per procedure of Sharma et al. [13]. After ashing, the residue was dissolved in nitric acid to a final solution concentration of $0.16 \mathrm{M}$. Fruit calcium content was measured by atomic absorption spectrophotometer. Samples of affected and normal fruit were drawn from the storage, and from each fruit, 3 - $4 \mathrm{~mm}$ thick longitudinal slices were taken, reducing the total weight of the sample to $50-60 \mathrm{~g}$.

\subsubsection{Estimation of Lipoxygenase (LOX) Activity}

\section{1) Preparation of Substrate}

The substrate was prepared as per the procedure described for apple by Feys et al. [14] with slight modifications. First, linolenic acid $(0.1 \mathrm{ml})$ was dissolved in $1 \mathrm{ml}$ $0.1 \mathrm{~N} \cdot \mathrm{NaOH}$ solution. To this, $150 \mu \mathrm{L}$ Triton-X-100 was added. The solution was emulsified in an Ultra Turrax for $2 \mathrm{~min}$, and diluted to $50 \mathrm{ml}$ with distilled water. Blank was prepared similarly by using substrate solution. The substrate and the blank were stored at $4^{\circ} \mathrm{C}$ in dark until use.

2) Preparation of Crude Enzyme Extract

Crude enzyme extract was prepared at $4{ }^{\circ} \mathrm{C}$, following the method of Axelrod et al. [15] with minor modifications. Diced $1 \mathrm{~g}$ apple fruit was homogenized in pre-chilled pestle and mortar by mixing in ice cooled $10 \mathrm{ml}$ EDTA. The homogenate was centrifuged at $15,000 \times \mathrm{g}$ for $20 \mathrm{~min}$ at $4^{\circ} \mathrm{C}$ and supernatant was used for assay of lipoxygenase activity. 
3) Measurement of LOX Activity

LOX enzyme assay was carried out as per the procedure of Axelrod et al. [15] with minor modifications. Firstly, $50 \mu \mathrm{L}$ of enzyme extract was added to $2.50 \mu \mathrm{l}$ of substrate solution in a cuvette, mixed thoroughly and absorbance was recorded at $234 \mathrm{~nm}$ in a spectrophotometer (Double beam UV-VIS spectrophotometer UV5704SS) for $3 \mathrm{~min}$ at $30 \mathrm{sec}$ interval. LOX activity was expressed as " $\mu$ moles $\min ^{-1} \mathrm{~g}^{-1} \mathrm{FW}$ ".

\subsection{Statistical Design and Data Analysis}

The data generated for different parameters were pooled and subjected to analysis as per standard procedures [16]. The significance of the treatments was determined by developing ANOVA and the means were compared by calculating critical difference (C.D.).

\section{RESULTS AND DISCUSSION}

\subsection{Effects on Fruit Color}

Results of the study have revealed that fruit bagging has significantly influenced the color development in apples. Bagged apples with light-yellow bags resulted in the development of attractive red color over non-bagged apples (Figure 1). Conversely, the yellow/green color development was suppressed by bagging. Hunter "a" value, which is indicative of red color, was much higher (52) in the bagged apples than non-bagged ones (38), which slightly decreased during storage (Figure 1). Fruit color is the basic point of attraction for the consumers. Attractive color improves the physical appearance of the fruit, which helps to get better price in the domestic or export market. Earlier studies have reported that fruit bagging in apple inhibited color development, however it has now been established that fruit bagging is an effec-

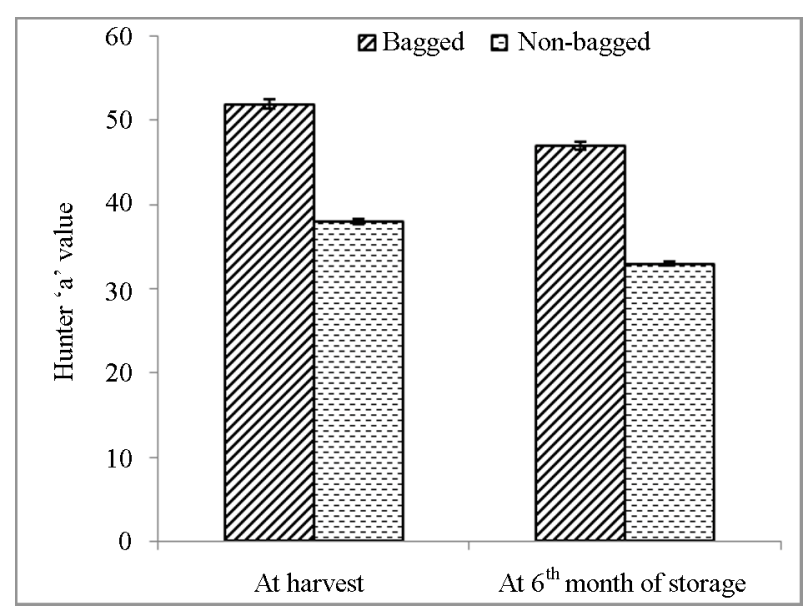

Figure 1. CIB Hunter "a" values in bagged and non-bagged Delicious apples at harvest and after $6^{\text {th }}$ month of storage at $2^{\circ} \mathrm{C}$ $\pm 1{ }^{\circ} \mathrm{C}$ and $90 \%-95 \% \mathrm{RH}$. Data are the mean of 30 fruits across three replications. Vertical bars indicate $\pm \mathrm{SE}$. tive way to promote anthocyanin synthesis and improve fruit coloration in apples $[17,18]$. It is believed that bagging increases light sensitivity of fruit and stimulates anthocyanin synthesis when fruits are re-exposed to light after bag removal $[19,20]$. Bagged fruits are capable of synthesizing anthocyanin when they were exposed to light for few days before the actual date of harvest [18]).

\subsection{Effect on Fruit Firmness, Ca Content and LOX Activity}

Fruit firmness is an important indicator for harvesting of fruit at appropriate maturity, which also determines the post harvest life of fruit. In this study, we observed that fruit bagging has affected the fruit firmness. At harvest, bagged fruits had higher firmness $(38.6 \mathrm{~N})$ than non-bagged fruits $(32.0 \mathrm{~N})$, and higher firmness was also maintained during storage of apples, yet it declined sharply during storage (Figure 2(a)). Only a few studies have been conducted on this aspect, which revealed that pre-harvest fruit bagging can influence the fruit firmness at harvest. For example, Bentley and Viveros [21] reported that fruit firmness of "Granny Smith" apples was improved by brown paper bags when done at golf-size of fruit development. However, Hofman et al. [4] reported that fruit firmness was not affected by white paper bag in mango.

Further, there was a significant effect of fruit bagging on fruit $\mathrm{Ca}$ contents and LOX activity at harvest and during storage. Bagged fruits also maintained higher level of $\mathrm{Ca}(5.38 \mathrm{mg} / 100 \mathrm{~g})$ than non-bagged fruits $(4.58$ $\mathrm{mg} / 100 \mathrm{~g}$ ) at harvest (Figure 2(b)), and the LOX activity in the bagged fruits was much lower $\left(1.38 \mu\right.$ moles min $^{-1}$ $\left.\mathrm{g}^{-1} \mathrm{FW}\right)$ than non-bagged fruits $\left(1.82 \mu\right.$ moles $\min ^{-1} \mathrm{~g}^{-1}$ FW) (Figure 2(c)), which increased sharply with increase in storage period, being maximum at the end of $6^{\text {th }}$ month of storage (Figure 3). Fruits contain several nutrients, which contribute to their quality. Since fruit bagging is usually done in the orchard during fruit development stage, hence it may subsequently influence the nutrient composition of fruits. For example, Kim et al. [20] reported that fruit bagging in pear helped in increasing $\mathrm{Ca}$ content but the contents of $\mathrm{N}$ and $\mathrm{P}$ were not significantly affected by bagging. Further, the contents of $\mathrm{K}, \mathrm{Ca}$, $\mathrm{Mg}$ were decreased by $9.6 \%, 38.9 \%$ and $6.7 \%$, respectively [22]. Similarly, Wang et al. [23] found that $\mathrm{Ca}$ contents in the bagged apple fruits were higher than unbagged ones, and the incidence of bitter pit in the bagged fruits was lower than that in the un-bagged fruits. In contrast, bagging in "Keitt" mango reduced the Ca concentration in fruits [4]. However, Amarante et al. [15] reported that pre-harvest bagging of pear did not affect flesh content of N, P, K, Ca, and Mg. Similarly, Wang et al. [24] reported no significant effect of bagging on fruit $\mathrm{Ca}$ content in fruit peel of "Huangguan" pear. Lower 


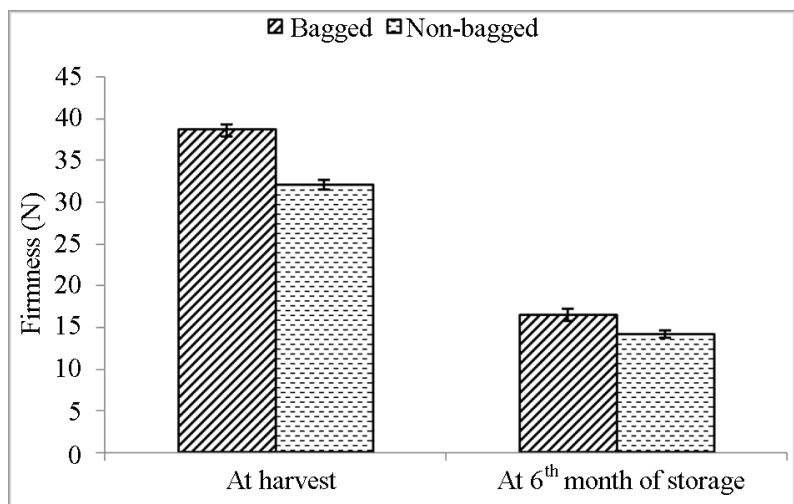

(a)

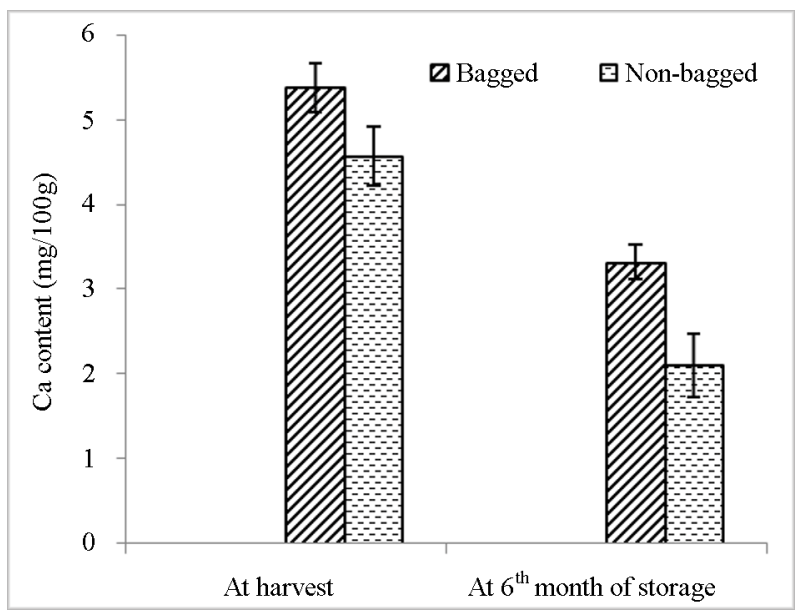

(b)

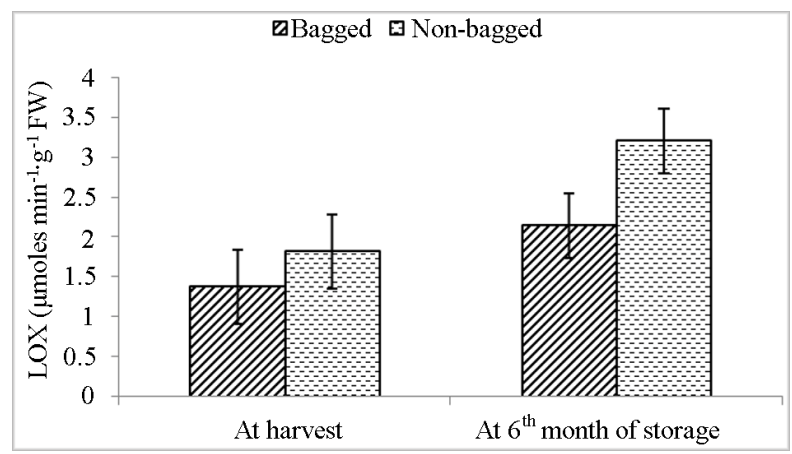

(c)

Figure 2. Fruit firmness (a), calcium content (b) and lipoxygenage activity (c) in bagged and non-bagged Delicious apples at harvest and after $6^{\text {th }}$ month of storage at $2^{\circ} \mathrm{C} \pm 1{ }^{\circ} \mathrm{C}$ and $90 \%$ $95 \%$ RH. Data are the mean of 30 fruits across three replications. Vertical bars indicate $\pm \mathrm{SE}$.

LOX activity in bagged apples indicates that bagged apples were less senescent than non-bagged apples.

\subsection{Effects on Total Phenolic Content and AOX Activity}

Our study has revealed that fruit bagging has significantly influenced total phenolics contents, AOX activity

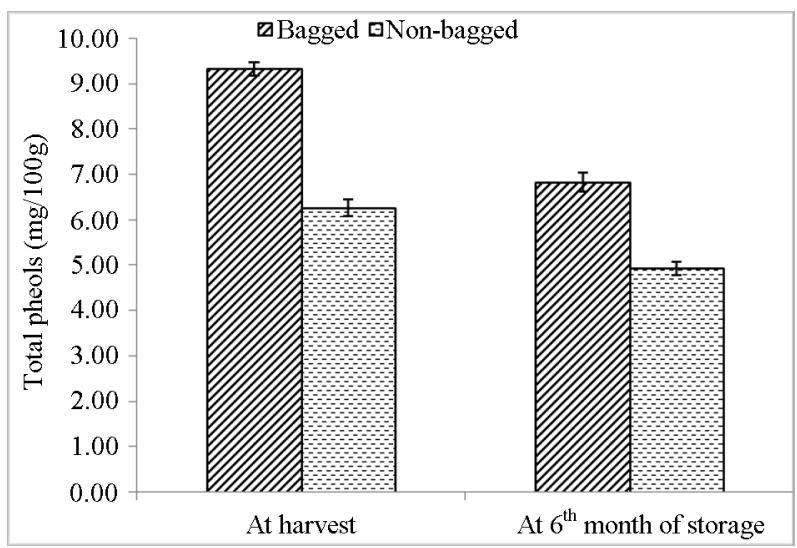

(a)

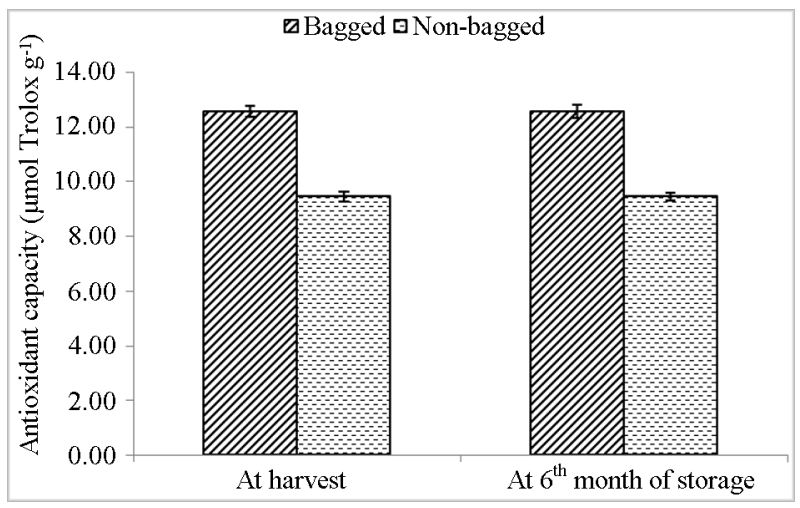

(b)

Figure 3. Total phenolics (a) and antioxidant activity (b) in bagged and non-bagged Delicious apples at harvest and after $6^{\text {th }}$ month of storage at $2^{\circ} \mathrm{C} \pm 11^{\circ} \mathrm{C}$ and $90 \%-95 \%$ RH. Data are the mean of 30 fruits across three replications. Vertical bars indicate $\pm \mathrm{SE}$.

and fruit eating quality attributes such as soluble solids and ascorbic acid contents significantly (Figure 3(a)). Bagged apples contained higher levels of phenolics ( 9.3 mg GAE/100g pulp) and exhibited higher AOX activity $\left(12.6 \mu\right.$ moles Trolox $\left.\mathrm{g}^{-1}\right)$ at harvest, which decreased during storage but the level was higher in bagged fruits (Figure 3(b)). Literature reveals that the effects of bagging on phenolic compounds of fruits have given contradictory information, which may reflect differences in cultivar, bagging material, date of bagging, period of bagging, date of bag removal and climatic conditions. For example, Ju et al. [19] reported that simple phenol concentration increased with bagging up to 60 days and then declined in "Delicious" apple. Similarly, Hudima and Stamper [25] reported that bagging of "Conference" pears increased some phenolic compounds such as epicatechin and caffeic acid in skin. In contrast, Xu et al. [8] reported that the total phenolic and flavonoid contents in loquat were decreased by bagging treatments, which lowered total antioxidant capacity (AOX) of the fruit. Yet, Wang et al. [23] reported that bagging did not affect 


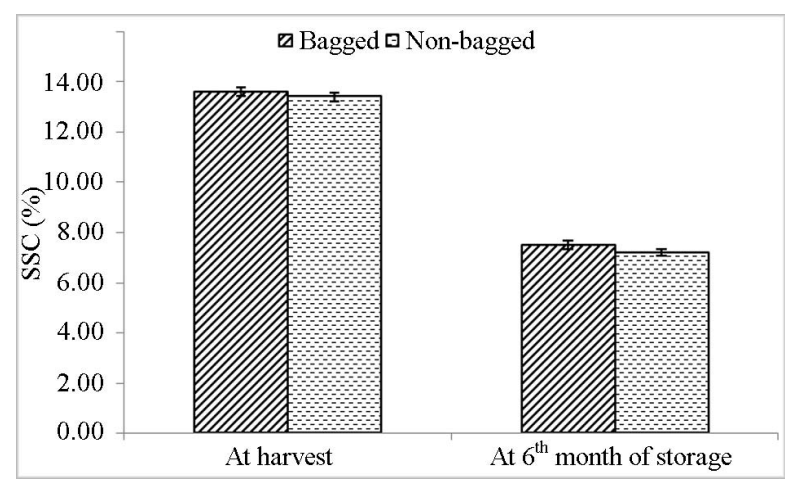

(a)

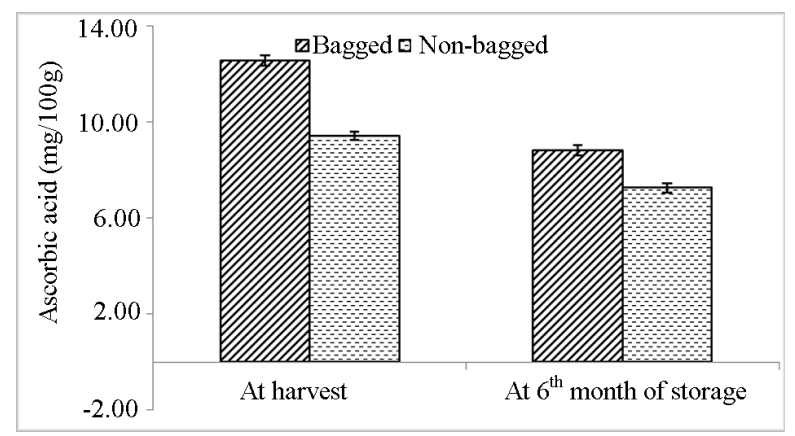

(b)

Figure 4. Soluble solids content (a) and ascorbic acid content (b) in bagged and non-bagged Delicious apples at harvest and after $6^{\text {th }}$ month of storage at $2^{\circ} \mathrm{C} \pm 1{ }^{\circ} \mathrm{C}$ and $90 \%-95 \% \mathrm{RH}$. Data are the mean of 30 fruits across three replications. Vertical bars indicate $\pm \mathrm{SE}$.

chlorogenic acid and catechol contents of either fruit peel or flesh in "Wanmi" peach.

\subsection{Effect on Eating Quality Attributes}

The ultimate aim of the producer is to produce fruits of better quality, and consumer also wants to have fruits of high quality. Eating quality of fruit includes attributes such as total soluble solids, acidity etc. It appears from our study that bagged apples had fairly higher level of soluble solids $\left(13.6^{\circ} \mathrm{B}\right)$ and ascorbic acid content $(28.6$ $\mathrm{mg} / 100 \mathrm{pulp}$ ) at harvest than non-bagged apples (Figures 4(a) and (b))., which decreased during storage but was maintained at a higher level than non-bagged apples. Several studies have reported increase in fruit quality attributes following fruit bagging. For example, Bentley and Viveros [21] reported that fruit sweetness of "Granny Smith" apples was improved by brown paper bags when it was done at golf-size of fruit development. Similarly, improvement in soluble solids has also been reported in loquat [8], "Red Globe" grapes [26], peach [27], guava [28], pear [29], mango [30] and litchi [31].

\section{CONCLUSION}

Based on these observations, it can be concluded that fruit bagging with spun-bounded fabric light-colored yellow bags in Delicious apples is quite effective in improving fruit color and maintaining fruit quality at harvest and during storage. It is a simple, cost-effective and ecofriendly technology, which has positive effects on apple fruits.

\section{REFERENCES}

[1] Chadha, K.L. and Awasthi, R.P. (2005) The apple. Malhotra Publishing House, New Delhi.

[2] Sharma, R.R., Singh, D. and Singh, R. (2009) Biological control of postharvest diseases of fruits and vegetables by microbial antagonists: A review. Biological Control, 50, 205-221. doi:10.1016/j.biocontrol.2009.05.001

[3] Kitagawa, H., Manabe, K. and Esguerra, E.B. (1992) Bagging of fruit on the tree to control disease. Acta Horticulturae, 321, 871-875.

[4] Hofman, P.J., Smith, L.G., Joyce, D.C., Johnson, G.L. and Meiburg, G.F. (1997) Bagging of mango (Mangifera indica cv. "Keitt") fruit influences fruit quality and mineral composition. Postharvest Biology and Technology, 12, 83-91. doi:10.1016/S0925-5214(97)00039-2

[5] Joyce, D.C., Beasley, D.R. and Shorter, A.J. (1997) Effect of pre-harvest bagging on fruit calcium levels, and storage and ripening characteristics of "Sensation" mangoes. Australian Journal of Experimental Agriculture, 37, 383389. doi:10.1071/EA96074

[6] Tyas, J.A., Hofman, P.J., Underhill, S.J.R. and Bell, K.L. (1998) Fruit canopy position and panicle bagging affects yield and quality of "Tai So" lychee. Scientia Horticulturae, 72, 203-213. doi:10.1016/S0304-4238(97)00125-8

[7] Amarante, C., Banks, N.H. and Max, S. (2002) Effect of pre-harvest bagging on fruit quality and Postharvest physiology of pears (Pyrus communis). New Zealand Journal of Crop and Horticultural Science, 30, 99-107. doi:10.1080/01140671.2002.9514204

[8] Xu, H.X., Chen, J.W. and Xie, M. (2010) Effect of different light transmittance paper bags on fruit quality and antioxidant capacity in loquat. Journal of Science of Food and Agriculture, 90, 1783-1788.

[9] Witney, G.W., Kushad, M.M. and Barden, J.A. (1991) Induction of bitter pit in apple. Scientia Horticulturae, 47, 173-176. doi:10.1016/0304-4238(91)90039-2

[10] Fan, X. and Mattheis, J.P. (1998) Bagging "Fuji" apples during fruit development affects color development and storage quality. HortScience, 33, 1235-1238.

[11] Singleton, V.L. and Rossi Jr., J. A. (1965) Colorimetry of total phenolics with phosphomolybdic-phosphotungstic acid reagents. Ameican Journal of Enology and Viticulture, 16, 144-158.

[12] Apak, R., Guclu, K., Ozyurek, M. and Karademir, S.E. (2004) Novel total antioxidants capacity index for dietary polyphenol and vitamins $\mathrm{C}$ and $\mathrm{E}$ using their cupric ion reducing capability in the presence of neocuproine: CUPRAC method. Journal of Agriculture and Food Chemistry, 52, 7970-7981. doi:10.1021/jf048741x 
[13] Sharma, R.R., Pal, R.K., Singh, D., Singh, J., Dhiman, M.R. and Rana, M.R. (2012) Relationships between storage disorders and fruit calcium contents, lipoxygenase activity, and rates of ethylene evolution and respirationin "Royal Delicious" apple (Malus x domestica Borkh.). Journal of Horticultural Science and Biotechnology, 87, 367-373.

[14] Feys, M., Naesens, W., Tobback, P. and Maes, E. (1980) Lipoxygenase acitivty in apples in relation to storage and physiological disorders. Phytochemistry, 19, 1009-1011. doi:10.1016/0031-9422(80)83048-2

[15] Axelrod, B., Cheesbrough, T.M. and Leakso, S. (1981) Lipoxygenase from soybeans. Methods Enzymology, 7, 443-451.

[16] Panse V.G. and Sukhatme, P.V. (1984) Statistical methods for agricultural workers. Third Edition, Indian Council of Agricultural Research, New Delhi.

[17] Ritenour, M., Schrader, L., Kammereck, R., Donahue, R. and Edwards, G. (1997) Bag and liner color greatly affect apple temperature under full sunlight. HortScience, 32, 272-276.

[18] Ju, Z. (1998) Fruit bagging, a useful method for studying anthocyanin synthesis and gene expression in apples. Scientia Horticulturae, 77, 155-164. doi:10.1016/S0304-4238(98)00161-7

[19] Ju, Z.G., Yuan, Y., Liu, C. and Xin, S. (1995) Relationships among phenylalanine ammonia-lyase activity, simple phenol concentrations and anthocyanin accumulation in apple. Scientia Horticulturae, 61, 215-266. doi:10.1016/0304-4238(94)00739-3

[20] Kim, Y.K., Kang, S.S., Cho, K.S. and Jeong. S.B. (2010) Effects of bagging with different pear paper bags on the color of fruit skin and qualities in "Manpungbae". Korean Journal of Horticultural Science and Technology, 28, 3640.

[21] Bentley, W.J. and Viveros, M. (1992) Brown-bagging "Granny Smith" apples on trees stops codling moth damage. California Agriculture, 46, 30-32.

[22] Lin, C.F. (2008) Effects of bagging on quality and nutri- ent content of "Jinfeng" pear. Journal Gansu Agricultural University, 2, 2-19.

[23] Wang, Y.J., Yang, C.X. , Liu, C.Y., Xu, M., Li, S.H., Yang, L. and Wang, Y.N. (2010) Effects of bagging on volatiles and polyphenols in "Wanmi" peaches during endocarp hardening and final fruit rapid growth stages. Journal of Food Science, 75, 455-460. doi:10.1111/j.1750-3841.2010.01817.x

[24] Wang, Y.T., Li, X., Li, Y., Li, L.L. and Zhang, S.L. (2011) Effects of bagging on browning spot incidence and content of different forms of calcium in "Huangguan" pear fruits. Acta Horticulturae Sinica, 38, 1507-1514.

[25] Hudina, M. and Stampar, F. (2011) Effect of fruit bagging on quality of "Conference" pear (Pyrus communis L.). European Journal of Horticultural Science, 76, 410-414.

[26] Zhou, X.B. and Guo, X.W. (2005) Effects of bagging on the fruit sugar metabolism and invertase activities in "Red Globe" grape during fruit development. Journal of Fruit Science, 26, 30-33.

[27] Kim, Y.H., Kim, H.H., Youn, C.K. Kweon, S.J., Jung, H.J. and Lee, C.H. (2008) Effects of bagging material on fruit coloration and quality of "Janghowon Hwangdo" peach. Acta Horticulturae, 772, 81-86.

[28] Singh, B.P., Singh. R. A., Singh, G. and Killadi, B. (2007) Response of bagging on maturity, ripening and storage behaviour of winter guava. Acta Horticulturae, 735, $597-$ 601.

[29] Lin, J., Wang, J.H., Li, X.J. and Chang, Y.H. (2012) Effects of bagging twice and room temperature storage on quality of "Cuiguan" pear fruit. Acta Horticulturae, 934, 837-840

[30] Watanawan, A., Watanawan, C. and Jarunate, J. (2008) Bagging "Nam Dok Mai \#4" mango during development affects color and fruit quality. Acta Horticulturae, 787, 325-328

[31] Debnath, S. and Mitra, S.K. (2008) Panicle bagging for maturity regulation, quality improvement and fruit borer management in litchi (Litchi chinensis). Acta Horticulturae, 773, 201-208. 